ENSAYO

\title{
UNIVERSALISMO Y COSMOPOLITISMO EN LA TEORÍA DE JÜRGEN HABERMAS*
}

\author{
Daniel Chernilo
}

Este artículo indaga en la importancia que el tema del cosmopolitismo ha adquirido en los escritos recientes de Jürgen Habermas. Para lograr ese objetivo, se explican en primer término los fundamentos filosóficos de la pretensión universalista en que se basa el cosmopolitismo. Para ello se reconstruyen los orígenes históricos del cosmopolitismo, su relación con las teorías premodernas del derecho natural y su primera formulación específicamente moderna en la obra de Immanuel Kant. En segundo lugar, se exponen los lineamientos centrales de la versión habermasiana del cosmopolitismo en com-

Daniel Chernilo. Sociólogo de la Universidad de Chile y doctor en sociología de la Universidad de Warwick (Inglaterra). Académico del Departamento de Sociología de la Universidad Alberto Hurtado e investigador adjunto del Centro de Teoría Social de la Universidad de Warwick. Correo electrónico: dchernil@uahurtado.cl.

* Este texto no habría sido posible sin el apoyo y generosidad intelectual de Robert Fine, cuya convicción de que el cosmopolitismo es un programa teórico y normativo fundamental para entender el presente es un estímulo y un ejemplo permanente. El autor agradece también a Aldo Mascareño sus siempre sugerentes ideas, precisiones y críticas a las distintas versiones de este trabajo. Aldo y Robert no comparten todos mis argumentos y obviamente no son responsables de mis errores.

Este artículo forma parte del proyecto FONDECYT "La sociología latinoamericana ante la universalidad de la diferenciación funcional y del cosmopolitismo" (107082). 
paración con las formulaciones kantianas. Finalmente, el artículo muestra que el giro cosmopolita reciente de Habermas no sólo es coherente con el universalismo filosófico de su obra anterior sino que ha de ser entendido como un corolario normativo necesario de la propia teoría.

\section{E}

ste artículo indaga en la importancia creciente que el tema del cosmopolitismo ha adquirido en los escritos de Jürgen Habermas a contar de los años noventa. Sin duda la presencia del cosmopolitismo en la obra reciente de Habermas responde a la evaluación que el autor hace de eventos más o menos recientes como la caída del muro de Berlín y de procesos históricos como la globalización económica y el proyecto de la Unión Europea (Habermas, 2004). Mi tesis, sin embargo, es que el giro cosmopolita que se aprecia en su trabajo no responde principalmente a cuestiones de tipo empírico, sino que debe ser entendido más bien como un corolario normativo necesario que emerge del universalismo filosófico en el que se funda el conjunto de su obra anterior. A pesar de la ausencia de referencias explícitas al tema en su obra temprana, este artículo argumenta que un horizonte cosmopolita viene inscrito en el proyecto intelectual habermasiano desde sus inicios.

La relevancia actual del cosmopolitismo comienza a acreditarse con las evaluaciones normativas que siguieron a las descripciones de la globalización que inundaron las ciencias sociales de los años noventa (Fine y Chernilo, 2004; Held, 1995). Con ello el cosmopolitismo se consolida como un programa de investigación empírico relevante para el conjunto de las ciencias sociales contemporáneas (Beck y Sznaider, 2006; Calhoun 2002; Fine 2006b; Fine y Boon, 2007; Vertovec y Cohen, 2002; Zolo, 1999). Sin embargo, no todas las versiones del cosmopolitismo contemporáneo son igualmente capaces de hacer frente a los desafíos explicativos y normativos del presente. En su tardío Derecho de Gentes, por ejemplo, John Rawls (1999) despliega un modelo cosmopolita puramente normativo y altamente sofisticado. De un modo similar, Ulrich Beck (2000) ha hecho del cosmopolitismo una agenda de investigación concreta para la sociología. Mi punto de partida en este trabajo es que, dado su alto nivel de abstracción, el cosmopolitismo de Habermas se muestra superior tanto a aquellas versiones exclusivamente normativas (Caney, 2002) como a aquellas que se contentan con el mero registro narrativo de procesos empíricos (Chernilo, 2006a). La perspectiva cosmopolita de Habermas es la única que, hasta el momento al menos, se ha mostrado capaz de afrontar con éxito el desafío de producir 
simultáneamente una descripción empírica pertinente, una explicación teóricamente consistente y un juicio normativo bien fundamentado.

La tesis de un "giro" cosmopolita es en algún sentido similar a aquella que, a mediados de la década de los setenta del siglo XX, se usó para describir el cambio en la orientación teórica de Habermas. El así llamado giro lingüístico habermasiano es heredero tanto de la tradición filosófica alemana como de la filosofía anglosajona de la época (Lafont, 1993). Su objetivo era el refinamiento conceptual de la teoría, pues con él se incorporaban perspectivas y tradiciones filosóficas nuevas para resolver deficiencias que se constataban a nivel teórico o epistemológico. El interés reciente por el cosmopolitismo es diferente dado que no le resuelve a Habermas problemas teóricos de fondo sino que, por decirlo de algún modo, se le fue imponiendo lentamente a la argumentación habermasiana como una consecuencia normativa ineludible del programa teórico. El giro cosmopolita al que aquí me refiero hace explícito, con renovada fuerza, el sustrato último del proyecto normativo de Habermas. La diferencia es tal vez sutil pero no por ello menos importante. La centralidad del cosmopolitismo en la obra tardía de Habermas dice relación no tanto con un proceso de refinamiento estrictamente conceptual sino sobre todo con la explicación de los efectos normativos de la teoría de la acción comunicativa. Sin duda la perspectiva cosmopolita de Habermas ha de certificarse empíricamente pero su orientación de base es por cierto normativa. Con la idea de la doble validez jurídica y moral de los derechos humanos, con la tesis del tránsito hacia una constelación postnacional que pone en cuestión la posición del estado-nación como eje articulador del sistema de Naciones Unidas, con la búsqueda de un principio contrafáctico que permita justificar argumentativamente aquello que es mejor "para la especie humana en su conjunto", este giro cosmopolita es otra forma de expresar la intuición reguladora que cruza el casi medio siglo de producción intelectual de Habermas: ¿cómo es posible explicar el hecho de que en el marco de procesos de interacción social surja la noción a todas luces ficticia desde un punto de vista empírico, pero normativamente vinculante, de la igualdad formal entre individuos materialmente desiguales? El cosmopolitismo es, en definitiva, la última fórmula que Habermas encuentra para expresar en un lenguaje normativo el núcleo universalista que está en el centro de su programa teórico.

El texto se encuentra dividido en tres secciones. En primer lugar, se intenta mostrar la conexión intrínseca que existe entre universalismo y cosmopolitismo tanto a nivel histórico como conceptual. Para ello se hace un breve recuento de los orígenes y características principales del cosmopolitismo en el marco de su estrecha relación con el universalismo filosófico de 
las teorías del derecho natural. Esta primera sección se centra especialmente en la obra de Immanuel Kant, cuya condición paradigmática se explica por la traducción moderna que él hace de la tradición filosófica del cosmopolitismo de la Grecia clásica así como por su intento por romper con la carga metafísica de las teorías del derecho natural anteriores. La segunda sección está dedicada a reconstruir la visión habermasiana del cosmopolitismo. Para ello se presta especial atención a la reconstrucción que el propio Habermas hace del diseño institucional con que Kant introduce y justifica su proyecto cosmopolita. Habermas entiende el cosmopolitismo como uno de los programas teóricos inmanentes al proyecto moderno antes que como una tendencia reciente de los últimos años; como un marco normativo intrínsecamente universalista sobre la base de un apoyo irrestricto a la idea de derechos humanos universales; y como un marco institucional democrático cuya máxima expresión no es la formación de un único estado mundial sino la articulación de instancias decisorias a nivel local, nacional, regional y mundial. Finalmente, la última sección del artículo reconstruye estilizada pero sistemáticamente la relación entre la pretensión universalista que está a la base de los distintos momentos del proyecto teórico de Habermas y las consecuencias cosmopolitas que se derivan de cada uno de ellos. Se intenta mostrar que una fuerte pretensión universalista caracterizaba ya los estudios tempranos de Habermas Historia y Crítica de la Opinión Pública ([1962] 1994) y Conocimiento e Interés ([1968] 1990a). Un universalismo similar, como ya se dijo, se aprecia con el giro lingǘstico que da vida a la Teoría de la Acción Comunicativa ([1981] 1989a) y con la más reciente incorporación de discusiones de filosofía política y legal en Facticidad y Validez ([1992] 1998). En todos los casos, el universalismo explícito de estos trabajos no sólo es compatible sino que sirve de soporte para la incorporación explícita del cosmopolitismo en su obra tardía.

\section{Universalismo filosófico, cosmopolitismo y derecho natural}

En esta primera sección quisiera proponer que hay una relación sistemática entre universalismo filosófico y cosmopolitismo. El corazón de la tradición cosmopolita es intrínsecamente universalista, puesto que propone la igualdad fundamental de los seres humanos con prescindencia de cualquier diferencia de clase, género, étnica, nacional, religiosa o cultural. Como programa normativo el cosmopolitismo no puede desplegarse sin un universalismo filosófico de base y ha de ser entendido como la consecuencia normativa necesaria de una pretensión universalista de conocimiento. Sin duda, la expresión concreta del vínculo entre universalismo y cosmopolitis- 
mo se ha mostrado históricamente cambiante. Pero en ese tránsito ambos han coevolucionado y tal coevolución puede ser metodológicamente reconstruida mediante el análisis de distintas teorías del derecho natural (Friedrich, 1964; Hochstrasser, 2000; Strauss, 1974).

Los inicios de la tradición cosmopolita pueden rastrearse en la época de la Grecia clásica. En su investigación de los orígenes premodernos del cosmopolitismo, el filósofo y matemático Stephen Toulmin plantea la tesis de que ya en la Grecia clásica aparece una primera idea de cosmopolitismo que se basa en el principio, por cierto altamente metafísico pero ya potencialmente universalista, de la unidad última del mundo social y el mundo natural:

Desde los inicios de la sociedad humana de gran escala, las personas se han preguntado sobre los vínculos entre el cosmos y la polis, el Orden de la Naturaleza y el de la Sociedad [...] más adelante encontramos a los filósofos estoicos fusionando los órdenes 'natural' y 'social' en un mismo todo. Cada cosa en el mundo [pensaban ellos] hace manifiesto de diversas formas un 'orden' que expresa la Razón que unifica tales cosas $[\ldots]$ la idea práctica de que los asuntos humanos están influenciados y proceden alineados con los asuntos divinos, se transforma en la idea filosófica de que la estructura de la Naturaleza refuerza un Orden Social racional. (Toul$\min , 1990:$ 67-68.)

El despliegue histórico de esta tradición intelectual no puede ser rastreado aquí en detalle, pero quisiera, al menos, sostener la tesis de que el horizonte universalista que la cita expresa no sólo no desaparece con el ocaso de la Grecia clásica sino que encontrará, sistemáticamente, formas de readecuarse a los tiempos. La demostración del origen común de universalismo y cosmopolitismo se expresa en el hecho de que la primera gran renovación de este proyecto universalista, el Código Romano que en 534 DC el emperador Justiniano mandó compilar, se sostiene justamente en las enseñanzas del estoicismo filosófico griego que está también a la base del cosmopolitismo (D’Entrèves, 1970: 23-25). El horizonte universalista de esta codificación temprana se expresa en un conjunto de atributos que en buena medida aún se consideran pertinentes para los efectos del debate contemporáneo que nos convoca: (1) el principio de la igualdad de los individuos ante la ley; (2) el rol del derecho como expresión de una idea de justicia que sirve para la resolución pacífica y razonada de conflictos y, de modo muy particular, (3) la tesis de una ontología estratificada que permite sostener la existencia de órdenes jurídicos distintos pero complementarios. En el códi- 
go de Justiniano se reconoce la existencia igualmente objetiva de un derecho o ley natural no susceptible de alteración humana, pero por cierto cognoscible racionalmente, un derecho o ley civil y un derecho de gentes que han de responder a necesidades humanas cambiantes pero que en cualquier caso han de adecuarse a los requerimientos objetivos de la ley natural (D’Entrèves, 1970: 28). El problema que permanece es justamente la cuestión de cómo han de establecerse y justificarse las relaciones y jerarquías entre estos distintos órdenes. El resguardo de la igualdad formal de los individuos, una idea de paz justa que se regula mediante el derecho y una concepción estratificada de órdenes jurídicos ontológicamente distintos son los elementos que en definitiva dan coherencia al núcleo de derecho natural del cosmopolitismo temprano y que, como tendremos ocasión de revisar en detalle, son intuiciones reguladoras que permanecen, a través de la obra de Kant, en la teoría de Habermas.

Una ontología estratificada similar está también a la base de las reformulaciones que las teorías del derecho natural experimentan mediante su recepción en el pensamiento medieval cristiano (Donelly, 1980; Lewis, 1940). Tanto en Agustín como en Tomás de Aquino, la pregunta por la autonomía y heteronomía del orden secular en relación con el divino está en el centro de sus reflexiones. Por una parte, la tesis heredada sobre la existencia de un plan perfecto y necesario que vale tanto para el orden natural como para el social no se pone en cuestión, a pesar de que se formula ahora en términos abiertamente religiosos. En eso justamente consiste la primacía de las leyes que rigen la Ciudad de Dios de San Agustín; ellas no son otra cosa que la expresión inmutable de la existencia de un ser y por tanto un orden superior. El principio estructurante de la unidad del mundo cambia —es una voluntad divina antes que un plan de la naturaleza —, pero su unidad e inmutabilidad se reafirman. Por otra parte, sin embargo, el postulado de la autonomía efectiva de la razón humana así como la necesidad de regular las prácticas sociales concretas e históricamente cambiantes de la Ciudad de Roma no permiten afirmar de modo mecánico o inmediato la primacía que en el plano teórico por cierto se le reconoce al orden divino. La ontología tripartita del código de Justiniano es ahora sólo doble: las leyes de la ciudad de dios y las de Roma (D’Entrèves, 1970: 39).

El siglo XVII marca el punto de inflexión de la secularización del principio universalista que está a la base de este cosmopolitismo temprano. La respuesta a la incertidumbre de las guerras y el cisma religioso que caracterizan ese período de la historia europea resultan en una incesante búsqueda de certezas y con ello la idea de razón deviene en el estándar que ha de unificar todos los distintos ámbitos de indagación científica. El reno- 
vado interés por el universalismo de la razón es la característica distintiva de la cosmópolis moderna. Con la publicación de tres de las obras centrales del pensamiento moderno en un lapso menor de quince años -el Discurso del Método de René Descartes (en 1637), los Principia Matemática de Isaac Newton (1642) y el Leviatán de Thomas Hobbes (1651)— se hace explícita la pretensión por fundamentar un principio que resulte válido en la explicación del mundo psíquico, natural y social. Nuevamente en palabras de Toulmin (1990: 127):

Cada cosa en el orden natural testifica (o se la puede hacer testificar) el dominio de Dios sobre la Naturaleza. Tal dominio se extiende sobre toda la fábrica del mundo natural y humano y es evidente en todos los niveles de la experiencia. Lo que Dios es a la Naturaleza, el Rey es al Estado. Es consistente que una Nación Moderna modelase su organización Estatal a partir de la estructura que despliega el mundo de la astronomía: el Roi Soleil, o Rey Sol, ejerce autoridad sobre círculos sucesivos de súbditos que conocen sus lugares y se mantienen en sus propias órbitas. Lo que Dios es a la Naturaleza y el Rey es al Estado, el Marido a su Esposa y el Padre a su familia [...] En todas estas formas, el orden de la Naturaleza y el de la Sociedad aparecen como gobernados por el mismo conjunto de leyes.

El fundamento universalista que está operando en estas teorías del derecho natural, tanto en las versiones religiosas como en las seculares, no remite directamente a la idea de cosmopolitismo en el sentido de ciudadanos del mundo al que aspiraba el estoicismo griego. Es sólo con Immanuel Kant, hacia finales del siglo XVIII, que se rescata explícitamente la tradición cosmopolita que se origina en ese movimiento filosófico (Nussbaum, 1997) y para ello la sintoniza con la pretensión universalista que constituye el centro de su filosofía (Cassirer, 1993). Para nuestros propósitos, los principales trabajos de Kant sobre el cosmopolitismo son sus escritos La Idea de una Historia Universal con Sentido Cosmopolita ([1784] 1994a) y La Paz Perpetua ([1795] 2001). Es sin duda adecuado destacar el carácter normativo que la idea de cosmopolitismo juega en la filosofía kantiana, pero no es menos cierto que la importancia que Kant le asigna al cosmopolitismo dice relación también con el hecho de que se trata de una tendencia que comienza a observarse empíricamente. Kant constata el incipiente surgimiento de un nuevo sentido de solidaridad colectiva que no se basa en cuestiones de nacionalidad o religión sino que toma como fundamento identitario esa idea 
de una única especie humana definida en un sentido fuertemente universalista. En palabras del propio Kant (2001: 51):

La comunidad más o menos íntima que se fue practicando entre los pueblos terrenales llegó ya hasta el extremo de que una violación del derecho cometida en un sitio, se hace sentir en todos los otros; de lo que se deduce que la idea de un derecho de ciudadanía mundial no es una fantasía jurídica, sino un necesario complemento del Código no escrito del derecho político y de gentes, que de ese modo se eleva a la categoría de derecho público de la Humanidad y redunda en beneficio de la paz perpetua, siendo la condición indispensable para que se pueda guardar la esperanza de un continuo acercamiento a un estado pacífico.

La principal innovación de Kant es usar la idea de cosmopolitismo para vincular el proyecto de un nuevo orden jurídico-institucional con lo que, como hemos visto, hasta el momento no era más que una intuición algo vaga. Kant se hace cargo de la ontología estratificada que marca a fuego las teorías del derecho natural, pero ofrece al mismo tiempo una guía para su dramática renovación. Kant distingue aquellas formas tradicionales de derecho de su tiempo: un "derecho Político de los hombres reunidos en un pueblo" (derecho civil), y un "derecho de Gentes o de los países y sus relaciones mutuas” (el derecho internacional). Pero concibe también un tercer estrato que es en algún sentido más general o universalisable que los dos anteriores, aunque ya no se trata ahora de un derecho o ley natural en sentido estricto. Kant habla, más bien, de un "derecho de la Humanidad, donde hay que tomar en cuenta seres y estados relacionados recíprocamente [...] una especie de ciudadanía universal entre seres humanos" (Kant, 1994a: 30). Este derecho de la humanidad se refiere a un tipo nuevo de regulación de las relaciones entre estados soberanos y los ciudadanos de esos estados y ha de fundarse en la pertenencia de los individuos a una especie humana que es concebida sin restricciones de ninguna clase. La ontología estratificada de las teorías del derecho natural anteriores queda así modificada. Por una parte, se vuelve a la versión de tres niveles. Por otra, esos niveles son todos ahora parte del mundo humano. Las leyes que rigen el orden divino quedan fuera del ámbito de la reflexión kantiana y lo mismo sucede con la afirmación de los principios generales que sirven para explicar las regularidades del mundo natural. La ley natural se reemplaza por la idea de un derecho de la humanidad cuya validez no se deriva de una necesidad metafísica sino de su condición de postulado universal de la razón práctica. Kant no recurre a fundamentaciones últimas de tipo religioso 
para avalar el universalismo normativo de su propuesta sino que recupera el fundamento laico y racionalista que era parte de la tradición filosófica del cosmopolitismo estoico y que había quedado subsumido durante la primacía de las versiones religiosas en la edad media. La justificación filosófica del universalismo kantiano se juega en el rol que él atribuye a las tres ideas regulativas de la razón pura: el Yo, la Naturaleza y Dios. Lo propio de estas ideas en su sentido kantiano es que, al mismo tiempo que se evita entrar en la cuestión de su existencia objetiva, ellas constituyen la condición de posibilidad del conocimiento empírico verdadero al interior de los ámbitos objetuales psíquico, natural y moral (Chernilo, 2004; Emmet, 1994; Kant, 2002).

En su orientación más práctica, la noción kantiana de cosmopolitismo es definida en un sentido crecientemente político. El cosmopolitismo de Kant apunta a que los estados trasciendan el "estado de naturaleza" en que se encuentran y puedan tender hacia el establecimiento de relaciones legalizadas entre ellos: "en sus relaciones recíprocas para los Estados no existe ninguna otra forma de salir de la situación anárquica — causa de guerras continuas- que sacrificar, como hacen los individuos, su salvaje y desenfrenada libertad y reducirse a leyes públicas coactivas, formando de ese modo un Estado de naciones que, aumentando incesantemente, llegue por fin a contener en su seno a todos los pueblos de la Tierra” (Kant, 2001: 47). La creación de una Federación Voluntaria de Estados de este tipo no es sin embargo la única novedad del cosmopolitismo kantiano. El núcleo de ese derecho propiamente cosmopolita radica en la forma en que los estados han de acoger y respetar los derechos de los forasteros que se encuentran en su territorio. Para Kant (1994a: 50), el trato al forastero ha de basarse en el "principio de hospitalidad", que se resume en la máxima siguiente: "nadie tiene más derecho que otro a estar en un sitio determinado del globo". El forastero es por definición aquel individuo que hace evidente la diversidad, particularidad y contingencia de cualquier forma de vida específica (en su idioma, sus rasgos físicos, sus hábitos alimenticios, su forma de vestir, etc.). La imagen del forastero sirve a Kant para reforzar que son precisamente tales diferencias las que nos hacen capaces de discernir aquello que nos hace uno con él: ese mínimo común denominador del que nadie puede ser despojado si ha de ser considerado un ser humano. Así, ninguna característica particular (étnica, nacional, religiosa, política o de otra clase) ha de impedir el trato digno y justo al forastero. En rigor, el principio de hospitalidad usa aquello que nos diferencia del forastero como el fundamento que nos obliga a tratarlo como uno de los 'nuestros'. El derecho cosmopolita se funda así tanto en el reconocimiento de la diferencia entre el forastero y el local, como en la filiación común de todos los individuos como miembros de 
la especie humana. El resultado de este análisis es la tesis de Kant (1994a: 60-61) de que, a fines del siglo XVIII, la humanidad se encuentra en un período de transición:

aunque este cuerpo político se halla todavía en estado de burdo proyecto, sin embargo, ya empieza a despertarse un sentimiento en los miembros, interesados en la conservación del todo; lo que nos da esperanza de que, después de muchas revoluciones transformadoras, será a la postre una realidad ese fin supremo de la Naturaleza, un estado de ciudadanía mundial o cosmopolita, seno donde pueden desarrollarse todas las disposiciones primitivas de la especie humana.

Una vez descritos los innegables avances que comportan las innovaciones filosóficas e institucionales propuestas por Kant, hemos de reconocer también que él no ha terminado por romper totalmente con los fundamentos metafísicos de las teorías del derecho natural —en sus versiones más racionalistas que religiosas- que lo precedieron. Esta continuidad se expresa, sobre todo, en el hecho de que Kant hace aún recaer buena parte de la plausibilidad de su argumento en aquella "insociable socialidad" de los seres humanos, es decir, en "su inclinación a formar sociedad que, sin embargo, va unida a una resistencia constante que amenaza permanentemente con disolverla" (Kant, 1994a: 46). En el principio octavo de su narración histórica con un sentido cosmopolita, Kant (1994a: 57) no tiene problemas en plantear la solución al dilema de la direccionalidad del proceso histórico de la humanidad en los siguientes términos: "se puede considerar la historia de la especie humana en su conjunto como la ejecución de un secreto plan de la Naturaleza, para la realización de una constitución estatal interiormente perfecta y, con este fin, también exteriormente, como el único estado en que aquella puede desenvolver plenamente todas las disposiciones de la humanidad”. En otras palabras, a finales del siglo XVIII, Kant todavía podía echar mano a las teorías del derecho natural de la época y justificar su adhesión al cosmopolitismo en razón de una direccionalidad histórica que viene garantizada por la Providencia (Fine, 2006a: 51-55). Kant confía en que la Providencia conducirá progresivamente a la creación de instituciones cosmopolitas para que así la humanidad en su conjunto esté en condiciones de disfrutar de un modo de vida también cosmopolita.

Desde el punto de vista de la teoría cosmopolita, en resumen, Kant puede ser entendido como el último de los cosmopolitas premodernos en tanto todavía hace uso de una idea de Providencia muy cercana a una concepción de ley de la naturaleza. Como ya el propio Hegel (1975) hiciese patente, Kant intenta pero no consigue romper definitivamente con los fun- 
damentos filosóficos de las teorías del derecho natural y que hasta ese momento habían permitido mantener conectados universalismo y cosmopolitismo. Y sin embargo, Kant es también el primero de los cosmopolitas modernos dado que intenta justificar el cosmopolitismo no sólo desde el punto de vista de su relevancia crecientemente empírica sino también como resultado institucional del mandato universalista de la razón práctica (Fine, 2003; Schneewind, 1993).

\section{El giro cosmopolita en la teoría reciente de Habermas}

El punto de entrada de Habermas al tema del cosmopolitismo es precisamente que la idea kantiana de una paz perpetua orientada en un sentido cosmopolita retiene, en el presente, tanto su encanto como su relevancia: "la puesta en práctica de un derecho cosmopolita expuesto de manera conceptual [...] permanece como una intuición reguladora del universalismo moral que guió a Kant en su proyecto" (Habermas, 1999a: 172). El primer elemento de la renovación habermasiana del proyecto cosmopolita de Kant viene por el lado de su estrategia de fundamentación: los doscientos años transcurridos entre los escritos de Kant y los del propio Habermas no han por cierto pasado en vano. Como acabamos de ver, el cosmopolitismo de Kant es todavía metafísico, puesto que hace depender su plausibilidad de una concepción de naturaleza humana conocida, inmutable y por cierto religiosamente aceptable. El cosmopolitismo de Habermas, por su parte, intenta justificarse desde un punto de vista crecientemente postmetafísico - o al menos desde la perspectiva de una argumentación moral postconvencional (Habermas 1985). El cosmopolitismo habermasiano no requiere de una idea de Providencia ni hace tampoco uso explícito de la idea de naturaleza humana, aunque es justo reconocer que sus nociones de competencia comunicativa y telos inmanente del lenguaje han sido interpretadas como una versión contemporánea de la tradición filosófica del derecho natural con las que, como revisamos ya, Kant quería romper (Fine, 2001: 21-23, Finnis, 1999; La Torre, 2006). Pero incluso si se aceptase que Habermas no se desliga completamente de tal carga metafísica, se trata en cualquier caso de un cosmopolitismo que sólo puede acreditarse desde dentro, es decir, de un cosmopolitismo que debe dar cuenta argumentativamente de la pertinencia y plausibilidad de su propia pretensión normativa. Para Habermas, el cosmopolitismo sólo puede justificarse como resultado de un procedimiento discursivo que potencialmente es universalmente inclusivo dado que "las determinaciones positivas se han tornado imposibles porque todo producto cognitivo sólo puede ya acreditarse merced a la racionalidad 
del camino por el que se ha obtenido, merced a procedimientos, y en última instancia a los procedimientos que implica el discurso argumentativo" (Habermas, 1990b: 48). La transición hacia un nuevo tipo de cosmopolitismo se traduce tanto en la transformación de la idea de razón práctica en razón comunicativa mediante su anclaje discursivo (Habermas, 2002) como en el rediseño de una arquitectura institucional internacional a partir de principios que puedan considerarse como efectivamente cosmopolitas. Es a este último punto al que dedicaremos ahora atención.

A juicio de Habermas, el equivalente contemporáneo de la idea kantiana del derecho de la humanidad son los derechos humanos, dado que éstos "representan el único fundamento reconocido para la legitimidad política de la comunidad internacional” (Habermas, 2000: 154); y el contenido cosmopolita de los derechos humanos radica justamente en que apelan a un "sentido de validez que transciende los ordenamientos jurídicos de los estados nacionales” (Habermas, 1999a: 175). Habermas destaca de los derechos humanos el hecho de que adoptan la forma de máximas morales: "estos derechos fundamentales comparten con las normas morales esa validez universal referida a los seres humanos en cuanto tales” (Habermas, 1999a: 176). Pero a diferencia de las normas morales, los derechos humanos han de ser considerados también como derecho positivo, dado que aspiran a contar con validez jurídica e instituciones que los hagan efectivamente aplicables. Por cierto, Habermas reconoce que no hemos llegado a un punto en que se pueda hablar de la institucionalización efectiva de una arquitectura institucional internacional con orientación cosmopolita basada en los derechos humanos, sino que hemos de describir nuestra situación, "en el mejor de los casos, como una situación de transición desde el derecho internacional hacia el derecho cosmopolita” (Habermas, 1999a: 167).

El mínimo común denominador de cualquier definición de cosmopolitismo es la idea del aseguramiento de una paz duradera mediante el derecho. Así entendido, sin duda que una forma posible para la consecución del objetivo cosmopolita de una paz duradera jurídicamente garantizada sería la conformación de una suerte de leviatán hobbesiano donde "la pacificación jurídica de la sociedad en el intercambio paradigmático de la obediencia de los sometidos al derecho" se justifica principalmente por el miedo, es decir, merced a "la garantía de protección que ofrece el estado" (Habermas, 2006: 119). En esta formulación, la respuesta a la pregunta por la forma institucional que mejor garantizaría la seguridad no sería otra que la idea de un estado mundial. En directa analogía al leviatán que saca a los individuos de su estado de naturaleza permanente para asociarlos, mediante un contrato social que es paradójicamente tan voluntario como inevitable en una comuni- 
dad sometida a derecho, lo que se requiere en este caso es un leviatán mundial que saque ahora a los estados de la situación de anarquía que prima entre ellos. El acto constituyente del estado de las teorías contractualistas se extrapola aquí a escala global —la así llamada "analogía doméstica" (Bottici, 2003) — y se asume con ello que un estado mundial habría de tomar el rol más bien policial de garantizar la seguridad de todos quienes vivirían en él.

La estabilidad y seguridad que sin duda son condición sine qua non de una situación de paz propiamente cosmopolita no se logran sin embargo solamente garantizando la integridad física de estados y/o individuos. El logro de esa estabilidad requiere también, y en eso tanto Habermas como Kant renuncian a la analogía de la salida del estado de naturaleza de Hobbes, de la creación de condiciones de vida en que los individuos pueden desarrollarse libremente. La idea cosmopolita de Kant se funda en una idea de libertad que, como mandato de la razón práctica, ha de regir tanto para los individuos como para los estados. Como ya hemos revisado, cosmopolita sería para Kant sólo aquella situación de paz duradera entre los estados que se regula mediante un marco jurídico legítimo y que a su vez reconoce los derechos fundamentales de sus habitantes en tanto individuos que pertenecen a la misma especie humana. Las guerras de agresión entre estados y el trato discriminatorio a los individuos en función de sus características o adscripciones particulares (de raza, religión, género o cualquier otra) han de ser rechazados moralmente y a la vez considerados como ilegales. Según Habermas, ya el propio Kant reconoce que "la función pacificadora del derecho" antes que garantizar la seguridad "se entrelaza más bien con la función de asegurar la libertad que cumple una situación jurídica que los ciudadanos pueden reconocer libremente como legítima” (Habermas, 2006: 119). Esta comprensión de la situación cosmopolita como aseguramiento simultáneo de la seguridad y la libertad lleva a que Kant se oponga a la idea del estado mundial. Este rechazo, que Habermas comparte, se fundamenta por cuestiones tanto pragmáticas como normativas. Un estado mundial que se justifica solamente a partir de la protección e integridad de sus miembros se encuentra en permanente riesgo de caer en el despotismo, puesto que la libertad queda siempre subordinada a la seguridad. El estado mundial estaría crónicamente ligado a un déficit de legitimidad democrática dado que la prueba de una adhesión libre y voluntaria a la institucionalidad vigente habría de manifestarse sólo esporádicamente.

Como vimos, la respuesta de Kant a la posibilidad de un estado mundial es su propuesta de una "asociación voluntaria de naciones". Habermas reconoce en ello un importante avance normativo, dado que Kant 
puede de esta forma reconocer y proteger la especificidad de formas particulares de vida colectiva que no son sustituibles o intercambiables. En la medida en que se organizan de forma republicana, es decir, de manera no despótica y bajo el imperio del derecho, los estados-nación han venido creando lentamente y a tropiezos las condiciones de solidaridad social sobre las que la democracia política y social puede efectivamente florecer. El orden cosmopolita al que se aspira no sólo no requiere sino que en rigor rechaza la eliminación o disolución de comunidades socio-políticas realmente existentes. No hay posición propiamente cosmopolita sin aquel nivel intermedio de organización social que se encuentra entre el individuo aislado como sujeto de derechos y la especie humana entendida como un todo. Una federación voluntaria de naciones así concebida tiene un conjunto de ventajas por sobre el estado mundial, puesto que en este último

los pueblos perderían junto con la soberanía de sus Estados la independencia nacional que ya habían conquistado, se pondría en peligro la autonomía de cada forma de vida colectiva. De acuerdo con esta lectura, la 'contradicción' consiste en que los ciudadanos de una república mundial obtendrían la garantía de la paz y la libertad sólo a costa de perder esa libertad sustancial que poseen como miembros de un pueblo organizado en la forma de un estado nacional [...] En último término, lo que inquieta a Kant es la alternativa entre el dominio mundial de un único gobierno monopolizador de la violencia y el sistema existente de varios Estados soberanos. Con la concepción sustitutoria de una 'asociación de naciones' busca una salida a esa alternativa. (Habermas, 2006: 125-126.)

El dilema del cosmopolitismo contemporáneo queda entonces planteado de la siguiente forma. Por un lado, es preciso aceptar que el fundamento cosmopolita del estado mundial se basa en el reconocimiento de que son los individuos y no los estados los sujetos últimos del derecho cosmopolita. Todos y cada uno de los habitantes de ese hipotético estado mundial serían igualmente sujetos de los mismos derechos. Pero para garantizar tales derechos individuales, el derecho cosmopolita de un estado mundial tendría necesariamente que disolver el derecho internacional que regula las relaciones entre estados. El estado mundial elide derecho cosmopolita y derecho civil, pues todo derecho sería ahora interno al único estado que efectivamente posee legitimidad; la ontología estratificada que hemos visto es patrimonio de la tradición cosmopolita desde sus inicios desaparecería definitivamente. El riesgo que ello comporta es que los ciudadanos de tal 
estado mundial estarían todos igualmente desprotegidos para resistir las posibles acciones arbitrarias de aquel leviatán mundial. Por otro lado, la objeción de Habermas a la idea de la asociación voluntaria de naciones con que Kant se opone a la idea de un estado mundial es que en tanto estamos hablando de una asociación voluntaria, Kant no consigue efectivamente explicar por qué los estados habrían de renunciar a aquella parte central de su soberanía que se encuentra encarnada en su derecho a declarar la guerra. La asociación de naciones de Kant es demasiado débil para sacar a los estados de su condición de crónica anarquía porque, en ausencia de una autoridad superior con capacidad de coacción efectiva, no hay garantía de que todos los otros estados habrían de actuar de la misma forma. La solución que Habermas propone requiere entonces la mantención de niveles jurídicos diferentes que se complementen y balanceen mutuamente.

En opinión de Habermas, entonces, Kant está operando con dos supuestos errados que lo dejan entrampado en la falsa alternativa entre un estado mundial potencialmente eficaz desde un punto de vista pragmático pero crónicamente deficitario desde un punto de vista normativo, y una federación voluntaria de naciones presumiblemente diversa pero con una debilidad endémica para imponer efectivamente sus decisiones. El primero de esos supuestos problemáticos es que Kant iguala el concepto jurídico de estado como aquellas "asociaciones de ciudadanos libres e iguales", con el concepto sustantivo de pueblo o "comunidad ética" que se diferencia de otros pueblos en razón de "la lengua, la religión y la forma de vida” (Habermas, 2006: 125). Esta igualación entre estado y nación o pueblo es una versión de lo que en el debate de la teoría social contemporánea ha tomado el nombre de nacionalismo metodológico (Chernilo, 2006a). Habermas reconoce que en sí mismo el estado-nación es condición necesaria mas no suficiente para el establecimiento de un orden cosmopolita. El estado-nación es una instancia que hasta el momento se ha mostrado imprescindible para la concreción de los distintos órdenes jurídicos que una situación cosmopolita ha de comprender, pero antes que una formación socio-política monolítica, autocontenida e inmutable, el estado-nación ha de ser concebido como históricamente elusivo, sociológicamente impreciso y normativamente ambiguo (Chernilo, 2007a). El segundo problema que Habermas distingue se deriva del hecho que Kant "concreta precipitadamente la idea bien fundamentada de una situación cosmopolita” (Habermas, 2006: 126) en el modelo de la República Francesa centralista, donde la soberanía estatal es indivisible y es ejercida siempre de forma centralizada. Un modelo federalista antes que centralista, piensa Habermas, le habría permitido a Kant entender que la soberanía popular puede ser efectivamente compartida, de forma tal que 
“los 'pueblos' de Estados independientes que restringen su soberanía a favor de un gobierno federal no pierdan necesariamente su particularidad y su identidad cultural” (Habermas, 2006: 127). Este modelo federal permite entonces concebir una organización del poder estatal que funcione en niveles diferenciados y fundamente tanto su legitimidad como su capacidad ejecutiva (De Grieff, 2002). Habermas concibe lo que podríamos denominar un cosmopolitismo federalista que es capaz de entregar el monopolio del uso de la fuerza legítima a una agencia específica, sin que ello signifique renunciar de forma absoluta a la autodeterminación efectiva de instancias intermedias en toda una serie de ámbitos igualmente relevantes para la vida colectiva.

$\mathrm{Si}$, como vimos, ya el propio Kant encontraba necesario hacerse la pregunta por la plausibilidad empírica del cosmopolitismo para caracterizar el proyecto moderno, el problema de la pertinencia descriptiva del cosmopolitismo es tanto más urgente para Habermas. La tesis habermasiana de la transición a la constelación postnacional de una sociedad mundial requiere de un anclaje que es tan descriptivo como normativo. No basta entonces con vincular el resurgimiento del interés por el cosmopolitismo como una forma de controlar o aminorar las consecuencias negativas de la globalización económica. Para Habermas, la pertinencia sustantiva del cosmopolitismo se juega en su capacidad para describir los eventos más controvertidos de los últimos años, como la intervención de la OTAN en Kosovo en 1999, el atentado a las Torres Gemelas el año 2001 y la invasión de los Estados Unidos y Gran Bretaña a Irak en el año 2003, ofreciendo al mismo tiempo una perspectiva normativa con la que evaluar tales fenómenos (Chernilo, 2006b). La conclusión que así surge es que el proyecto cosmopolita debe quedar asegurado no sólo desde el punto de vista de su adecuación normativa - “como la culminación lógica de los principios legales sobre los que se fundó la ilustración” (Fine y Smith, 2003: 470)— sino también desde un punto de vista jurídico-político. En el marco de las relaciones internacionales contemporáneas, señala Habermas, la cuestión más “controvertida es cómo podrían realizarse mejor estos fines: siguiendo el procedimiento jurídicamente establecido de una ONU inclusiva pero carente de fuerza y muy selectiva en sus decisiones; o más bien en virtud de una política con la que una potencia hegemónica bienintencionada establece unilateralmente un nuevo orden” (Habermas, 2006: 114-115). En el caso de Kosovo, por ejemplo, Habermas estuvo de acuerdo con el uso de la fuerza con el fin de evitar un genocidio, incluso a pesar de que tal intervención se llevó a cabo sin el respaldo legal que habría significado el apoyo explícito del Consejo de Seguridad de las Naciones Unidas. La reciente invasión a Irak, a la que Haber- 
mas se opone desde antes del inicio de las acciones militares, hace por su parte patente el riesgo asociado a la ausencia de un marco jurídico que permita delimitar con precisión la forma en que se actualizan los ideales cosmopolitas en las prácticas e instituciones internacionales.

Podemos resumir ahora cuáles son los atributos principales de la teoría cosmopolita en su versión habermasiana. En primer lugar, hemos visto que el cosmopolitismo habermasiano se opone a la idea del estado mundial en razón de su crónico déficit democrático. La idea de cosmopolitismo que Habermas defiende requiere de una legitimidad que sólo puede surgir de procedimientos e instituciones que permitan, potencialmente al menos, el asentimiento libre de todos los involucrados. Incluso si uno interpretase - contra la pretensión explícita del propio Habermas - que su noción de acuerdo normativo se funda en un principio trascendente análogo a aquel de las teorías del derecho natural, es preciso reconocer que su concepción universalista sólo puede acreditarse internamente, es decir, desde la perspectiva de los propios actores que intentan arribar a un consenso racional. En segundo término, Habermas entiende el cosmopolitismo como uno de los programas normativos inmanentes de la modernidad. En este punto, su posición se separa de otras propuestas contemporáneas, como la de Ulrich Beck (2004, 2006), para quien el cosmopolitismo contemporáneo se constituye en la expresión visible de un verdadero cambio epocal que se inicia sólo con el fin de la Guerra Fría. Mientras Habermas entiende que la relevancia del cosmopolitismo en el mundo contemporáneo se juega en el sopesar las continuidades y rupturas del pensamiento y formas institucionales modernas (Fine, 2004 y 2007), Beck exagera todo evento o tendencia que parece novedosa y con ello termina en una suerte de culto reificado a la novedad (Fine y Chernilo, 2004; Webster, 2002). Tercero, hemos visto que el derecho cosmopolita es para Habermas antes un complemento que un sustituto del derecho nacional e internacional. Cosmopolitismo y nacionalismo han coevolucionado durante la modernidad y no hay razón para verlos como opuestos (Delanty, 2006). Tanto la legitimidad como la efectividad de las instituciones cosmopolitas requieren del soporte efectivo de marcos jurídicos que se anclan a distintos niveles y con ello se renueva la tesis de una ontología jurídica estratificada que ha sido parte de la tradición cosmopolita desde sus inicios. En la formulación de Habermas, entonces, una situación propiamente cosmopolita es aquella que combina exitosamente instancias decisorias a nivel local, nacional, transnacional y global: ésa es la versión contemporánea de la ontología estratificada de órdenes jurídicos. El logro de este objetivo requiere que las instituciones se hagan compatibles con los fundamentos normativos del cosmopolitismo y si bien ello no es imposible, no es algo que venga tampoco automáticamente garantizado (Held, 1995). 


\section{El universalismo filosófico de la teoría habermasiana y sus consecuencias cosmopolitas}

Mientras la primera sección del artículo esbozó la conexión histórica y sistemática entre universalismo filosófico y cosmopolitismo a través de su relación con las teorías del derecho natural, la segunda reconstruyó la forma en que para Habermas el cosmopolitismo participa de la comprensión del mundo contemporáneo. El vínculo entre ambas secciones viene dado por la renovación de la tradición cosmopolita que Kant lleva a cabo, pues no es otro que el propio Kant quien establece el vínculo explícito entre universalismo filosófico y cosmopolitismo. Esta tercera sección muestra que también el cosmopolitismo habermasiano está anclado sobre una fuerte pretensión universalista de conocimiento. Al igual que en el caso de Kant, el núcleo de la teoría de Habermas está en su universalismo filosófico (Apel, 1994; McCarthy, 1987). La hipótesis que guía esta última sección es que la inclusión del cosmopolitismo como perspectiva normativa en la obra de Habermas es consistente con las decisiones conceptuales fundamentales de su teoría durante ya casi medio siglo: el cosmopolitismo ha de ser entendido como un corolario normativo que es interno al universalismo propio de la teoría de Habermas. Mi intención, por tanto, es rastrear de forma sistemática, aunque estilizada, la conexión entre universalismo y cosmopolitismo a lo largo del desarrollo intelectual del pensamiento de Habermas. Me interesa mostrar cómo se expresa tal relación entre universalismo y cosmopolitismo al interior de la propia teoría de Habermas. Para ello propongo analizar la pretensión universalista vis-à-vis el resultado normativo cosmopolita de los cuatro trabajos más importantes de Habermas: (a) Historia y Crítica de la Opinión Pública de 1962; (b) Conocimiento e Interés de 1968; (c) Teoría de la Acción Comunicativa de 1981, y (d) Facticidad y Validez de 1992.

(a) El primer estudio sistemático realizado por Habermas versa sobre el desarrollo de un tipo específico de razonamiento en y sobre lo público en Europa durante el siglo XVIII. Desde un punto de vista histórico, el vínculo de este primer trabajo con el cosmopolitismo se expresa en que la explicación de la aparición de esta esfera pública en la modernidad temprana coincide, en tiempo y lugar, con las tesis de Kant sobre el cosmopolitismo. La modernidad surge con el ocaso de la publicidad representativa que caracterizaba los regímenes absolutistas y con los primeros despuntes de un nuevo tipo de publicidad propiamente burguesa. En los cafés y clubes literarios de las principales ciudades europeas se comenzó a ensayar una renovada forma de discusión entre los comensales de esos salones en la que las 
diferencias materiales entre individuos quedaban suspendidas mientras duraba el intercambio de argumentos. Las revoluciones políticas americana y francesa de finales del siglo XVIII necesitan, como prerrequisito evolutivo si se quiere, de una infraestructura que se basa en la ampliación de esta nueva esfera público-política. La relación entre universalismo y cosmopolitismo en esta primera propuesta habermasiana se expresa también en un plano más explicativo puesto que la narrativa histórica del surgimiento de esas distintas esferas de discusión política nacionales está supeditada a la tesis del surgimiento de la modernidad como una única formación histórica que crecientemente abarca todo el globo. En este plano, las variaciones y diferencias nacionales en los procesos de formación de estas esferas público-políticas son expresiones particulares de un proceso histórico que ha de explicarse como logro evolutivo de la modernidad europea como una única formación civilizatoria.

No estoy por cierto sugiriendo que con Historia y Crítica de la Opinión Pública a inicios de la década del sesenta se haya anticipado el principal descubrimiento de la teoría de Habermas: la idea de acción comunicativa (Calhoun, 1992). Pero ello no impide destacar la continuidad efectiva que existe entre el intento por "desplegar el tipo ideal de la publicidad burguesa desde el contexto histórico del desarrollo inglés, francés y alemán” (Habermas, 1994: 3), las nociones de situación ideal de habla y consenso racional y los planteamientos aún más recientes sobre las características de una democracia deliberativa que se orienta en un sentido cosmopolita. En otras palabras, no hay incompatibilidad alguna entre la formulación de ese principio de publicidad temprano — “el interés público de la esfera privada de la sociedad burguesa deja de ser percibido exclusivamente por la autoridad y comienza a ser tomado en consideración como algo propio por los mismos súbditos” (Habermas 1994: 61), lo que más adelante será la "peculiar coacción sin coacciones que, merced a su capacidad de convencer, ejercen los mejores argumentos” (Habermas, 1989b: 103), que funge como fundamento de la noción de situación ideal de habla - y lo que recientemente han sido sus intervenciones sobre la formación de una esfera pública europea que se cristalizaría en la aprobación de la constitución de la unión (Habermas, 2001; Turner, 2004). En todos los casos, el resultado normativo de estos planteamientos es una idea de humanidad entendida en un sentido fuertemente universalista y que se basa en los principios de participación y asentimiento razonado de todos los involucrados.

(b) La intención del primer programa teórico en sentido estricto de Habermas es reintroducir un momento autorreflexivo en las prácticas cognoscitivas modernas en tanto "una crítica radical del conocimiento sólo es 
posible en cuanto teoría de la sociedad” (Habermas, 1990a: 9). En su trabajo Conocimiento e Interés de 1968, esta referencia a la posición privilegiada de la teoría de la sociedad implica, primero, que se critica la autocomprensión positivista de la actividad científica que toma como único modelo legítimo a las ciencias naturales. Se intenta con ello romper la analogía entre conocimiento empírico genuino y el método de las ciencias naturales. Al mismo tiempo, se amplía el abanico de posibilidades sobre el que modelar formas alternativas de conocimiento empírico, puesto que distintas prácticas cognoscitivas se insertan en distintos contextos existenciales. Si, dice Habermas, desde un punto de vista materialista se asume que cualquier forma de conocimiento ha de ser entendida también como praxis social, se concluye que serán precisamente tales contextos diferenciados de praxis los que han de permitir el deslinde de tipos de conocimiento igualmente diferenciados. Habermas reconoce entonces que la acción racional con arreglo a fines es una forma legítima de "estar en el mundo" y con ello legitima también el modelo cognoscitivo de las ciencias naturales a ella asociado. La racionalidad de fines que se expresa cognoscitivamente en las ciencias naturales es el tipo de praxis social que responde al contexto existencial de unas relaciones sujeto-objeto entre seres humanos y naturaleza. Aceptar que la racionalidad de fines es efectivamente un tipo de praxis no alienada no lleva a Habermas, sin embargo, a sostener que ella es la forma única o privilegiada de conocer el mundo. Pero comienza así su separación de la teoría crítica previa que había negado cualquier contenido sustantivamente racional a la racionalidad de fines. Mientras Marcuse relativiza y hace con ello históricamente prescindible tanto a la racionalidad de fines como a la propia ciencia moderna (Habermas, 1992), Adorno entiende la racionalidad de fines únicamente como una forma de praxis cosificada y con ello termina por abandonar la posibilidad misma de una orientación normativa de la acción (Habermas, 1993). Para Habermas, en cambio, se trata de reconocer que la racionalidad de fines es efectivamente un logro evolutivo de la modernidad sin por ello hipostasiar tal reconocimiento con la tesis de que la racionalidad de fines es un modelo adecuado para entender el diálogo y el entendimiento lingüístico entre individuos, es decir, las relaciones sujeto-sujeto.

El potencial cosmopolita de esta tesis se expresa en la forma que ha de adoptar el punto de vista normativo de una sociología crítica. Las formulaciones explícitas de ese principio normativo no están del todo logradas, pero ello no impide reconocer su compatibilidad con la del cosmopolitismo. A juicio de Cristina Lafont (2004: 33), por ejemplo, para Habermas "la tarea normativa de una teoría crítica de la sociedad es interpretada como la orientación hacia la identificación de intereses generalizables reprimidos”, es de- 
cir, intereses comunes a "todos los seres humanos racionales". O en palabras del propio Habermas (1987: 285), el tipo de reflexión que le interesa llevar a cabo ha de pensar "a partir de la perspectiva preproyectada ficticiamente de un sujeto generalizado de la acción social”. La sociología que el autor tiene en mente intenta imaginar aquello que puede ser mejor para la especie humana en su conjunto. Se trata de un ejercicio de imaginación puesto que ya no es posible determinar efectivamente aquello que es preferible para la especie humana y sin embargo el momento contrafáctico de ese ejercicio de anticipación se mantiene como el ideal regulativo que orienta la pretensión normativa del tipo de conocimiento en que Habermas está interesado. Los tres intereses de conocimiento que Habermas distingue en Conocimiento e Interés —el interés de control que corresponde a las ciencias naturales, el interés comunicativo que corresponde a la hermenéutica y las humanidades en general y el interés crítico o emancipatorio que corresponde a las ciencias reconstructivas como el psicoanálisis y la crítica marxista de la ideología - son todos igualmente representativos del modo de estar en el mundo del género humano y han de quedar expresados en prácticas cognoscitivas distintas e igualmente válidas.

(c) La pretensión universalista del proyecto teórico de Habermas toma un nuevo y ya definitivo rumbo con el giro pragmático-lingüístico que tiene lugar a inicios de la década de los setenta y que cristaliza en la publicación de su Teoría de la Acción Comunicativa en 1981. Mediante la incorporación de la filosofía y pragmática del lenguaje, de la idea de competencias humanas básicas y de la teoría de los actos de habla, Habermas construye la tesis del telos del lenguaje como descubrimiento empírico, es decir, como resultado de la orientación al entendimiento que subyace a toda interacción lingüísticamente mediada. En el centro de tal planteamiento está la tesis de la existencia de una racionalidad y acción comunicativa que tienen el mismo carácter de logro evolutivo de la modernidad que la racionalidad y acción instrumental: "la estructura teleológica es fundamental para todos los conceptos de acción. No obstante, los conceptos de acción social se distinguen por la forma en que plantean la coordinación de las acciones” (Habermas, 1989a, Vol. I: 146). Dado que la teoría de la acción comunicativa se hace cargo de la posición privilegiada del lenguaje en la constitución de lo social, el problema de la coordinación de las acciones — comunicativa en el mundo de la vida o estratégica en los sistemas de acción racionalqueda en el centro de la preocupación de Habermas.

Con ello no sólo se renueva la posibilidad de una teoría crítica de la sociedad moderna que sea capaz de justificar sus propios estándares normativos. El despliegue de esta pretensión universalista encuentra un nuevo 
impulso en la revisión del canon de la tradición sociológica. Desde sus inicios, la sociología es la ciencia social que ha hecho suya la pretensión universalista que está a la base del pensamiento ilustrado: "la sociología ha sido la única ciencia social que ha mantenido su relación con los problemas de la sociedad global. Ha sido siempre también teoría de la sociedad" (Habermas, 1989a, Vol. I: 20). La pertinencia de la sociología radica en su interés sistemático por comprender y evaluar la direccionalidad de los procesos recientes de racionalización social —la forma en que se resuelve el problema de la coordinación de las acciones. La sociología surge como una ciencia de lo social en general y no como una ciencia de las sociedades nacionales (Turner, 1990, 2006) y sus pretensiones conceptuales y metodológicas son compatibles con el universalismo normativo del cosmopolitismo (Chernilo y Mascareño, 2005). O, en los términos aquí preferidos, la pretensión fuertemente universalista de la sociología viene acompañada con un horizonte normativo cosmopolita y ambos se requieren para pensar el surgimiento y desarrollo de la modernidad (Chernilo, 2007b). En este tercer momento del pensamiento de Habermas el potencial cosmopolita se expresa en la tesis de una competencia interactiva o comunicativa generalizada que constituye, en un sentido enfático, a los individuos "en tanto sujetos capaces de lenguaje y acción” (Habermas, 1989b: 25). El objeto de estudio de la pragmática universal queda definido como "identificar y reconstruir las condiciones universales del entendimiento posible” (Habermas 1989b: 299). El potencial cosmopolita de la teoría de la acción comunicativa se muestra también en el papel de la distinción entre sistema y mundo de la vida como teoría general para describir, explicar y evaluar normativamente el surgimiento y características principales de la modernidad como una formación histórico-social con pretensiones y alcance universales.

(d) El desarrollo teórico de Habermas llega a lo que seguramente será su última formulación sistemática en el libro Facticidad y Validez. Sobre la base de los fundamentos sociológicos y normativos de la teoría de la acción comunicativa, el esfuerzo de Habermas se concentra ahora en desarrollar una teoría de la democracia y del estado de derecho también con pretensiones universalistas. Por un lado, Habermas revisa los fundamentos normativos de la teoría de la democracia y los somete a revisión a la luz de los principios de universalidad e inclusión. Por el otro, avanza un paso más en la teoría de los medios simbólicamente generalizados y reconstruye sociológicamente el derecho como un metamedio. Es decir, el derecho queda conceptualizado como aquel lenguaje social generalizado que se mantiene acoplado con el mundo de la vida por el lado de su inmanente referencia a la legitimidad y con los sistemas de acción racional por el lado de su eficacia 
pragmática (Chernilo, 2002). La teoría deliberativa de la democracia que así surge reflexiona directamente sobre los fundamentos históricos y normativos de las democracias modernas en el marco del estado-nación. Sin embargo, el horizonte de esa reflexión requiere desde sus inicios de un fundamento normativo que es independiente del estado-nación. Al afirmar que "la idea de derechos del hombre y la idea de soberanía popular han venido determinando la autocomprensión normativa de los estados democráticos de derecho hasta hoy”, Habermas (1998: 94) entiende que no es posible conceptualizar adecuadamente el núcleo democrático del estadonación - la soberanía popular - con prescindencia de una idea de derechos humanos universales. La importancia que Habermas le asigna a la reflexión sobre las relaciones entre democracia y derecho se justifica por la creciente relevancia que el cosmopolitismo adquiere desde el punto de vista de la intensificación de los procesos empíricos que comúnmente vienen asociados a la idea de globalización. Igualmente, las bases normativas del cosmopolitismo hacen del estado-nación un espacio demasiado estrecho para soportar y legitimizar los derechos y normas fundamentales sobre los que se basan las democracias modernas.

Desde el punto de vista histórico hay por cierto buenas razones para explicar el vínculo entre democracia y estado-nación, pero en el marco de una transición hacia una "constelación postnacional”, tal relación debe ser revisada (Habermas, 2000). En los años setenta del siglo pasado, Habermas (1975) se hizo parte del diagnóstico de una crisis de legitimación del estado de bienestar derivada de su incapacidad para garantizar el crecimiento económico sostenido que se requiere para financiar un sistema amplio de protección social, lo que a su vez acrecentaba el déficit de adhesión a la democracia política. Hoy en día, piensa Habermas, se constataría que una parte importante de los problemas más acuciantes de las sociedades modernas reparan sólo débilmente en los límites geográficos de los estados-nación y con ello el problema de la legitimación democrática parece irse trasladando desde lo que sucedía en el interior del estado-nación a aquello que tiene lugar al interior de la sociedad mundial. Calentamiento global, libre comercio, tráfico de drogas, violaciones a los derechos humanos, son todos problemas que requieren de la participación de instancias nacionales pero cuya comprensión, manejo y eventual solución escapa a las capacidades del estado-nación. Tanto el problema normativo de la legitimidad democrática como el práctico de la efectividad de las políticas públicas se juega ahora simultáneamente en esferas de toma de decisión subnacionales, nacionales, regionales, transnacionales y eventualmente globales. Lo que Habermas denomina en ese contexto la "función epistémica de la democracia" se expresa 
en las condiciones que hacen racional la participación en procesos de deliberación público-política: "un discurso racional se supone público e inclusivo, debe garantizar derechos de comunicación equitativos para los participantes, requiere de sinceridad y ha de difuminar cualquier tipo de fuerza que no sea la fuerza incoactiva del mejor argumento" (Habermas, 1999b: 332). Sin duda, la efectividad de un planteamiento tan abstracto radica en el tipo concreto de ámbitos institucionales en que trate de aplicarse. El horizonte cosmopolita del argumento queda en cualquier caso de manifiesto en el hecho de que no hay nada en él que presuponga o requiera de una forma socio-política específica, sea ésta el estado-nación o cualquiera otra. Así, si bien el tema del cosmopolitismo no aparece explícitamente en los escritos de Habermas sino hasta después de la publicación de Facticidad y Validez, hemos visto sin embargo que la pretensión universalista que subyace al programa teórico habermasiano en todas sus etapas hace que la inclusión del tema no sea ni sorpresiva ni traumática.

El reciente giro cosmopolita de la teoría de Habermas, y que se revisó en la sección anterior, es más una consecuencia lógica de la pretensión universalista que ha permanecido en estado latente a lo largo de su trayectoria intelectual que un nuevo descubrimiento. No hay tal cosa como un quiebre entre el "Habermas joven” y el "Habermas maduro" en relación al cosmopolitismo. Nada parecido a una ruptura epistemológica ha tenido lugar en su obra a este respecto, por lo que el reciente giro explícitamente cosmopolita debe ser visto más bien como la consumación de una orientación normativa que se encontraba en ciernes y que se deriva de los requerimientos internos de la propia teoría. Es la conexión inmanente entre universalismo y cosmopolitismo lo que lleva a Habermas a encontrar en el segundo una forma adecuada de dar expresión normativa a las pretensiones descriptivas del primero.

\section{Conclusión}

A principios del siglo XX, el sociólogo francés Émile Durkheim ya entendía las ideas de libertad individual, autodeterminación colectiva y cosmopolitismo como tres órdenes distintos que están igualmente basados en un principio universalista (Durkheim, 1966; Chernilo, 2007a). Para Durkheim no existía una única forma de resolver los posibles conflictos entre estos tres niveles y eso lo hacía sensible al hecho de que la exacerbación de cualquiera de ellos habría de conducir necesariamente a conflictos con los otros dos. El siglo pasado ha mostrado, sin duda con innecesaria crueldad, que un despliegue sin contrapesos de la autonomía individual conduce a 
situaciones de anomia, que sólo una delgada línea separa la autodeterminación nacional de prácticas abiertamente xenófobas y racistas, y que la negación del cosmopolitismo como orientación normativa despoja del estatus mismo de ser humano a grupos enteros y abre con ello las puertas de los campos de trabajos forzados, centros de tortura y cámaras de gases de dictaduras y regímenes totalitarios.

En nuestros días, y parafraseando la distinción kantiana entre una época de ilustración y una época ilustrada (Kant, 1994b), Robert Fine (2006b) encuentra que en un diagnóstico epocal actual aparece una tensión entre la idea de una época de cosmopolitismo — donde la idea de ciudadano del mundo ya no es una mera ficción sino que tiene una incipiente pero crecientemente nítida resonancia institucional- y una época cosmopolita - en la que buena parte de las instituciones y prácticas actualmente existentes aún no se fundan en esos ideales. La forma en que Habermas usa el cosmopolitismo queda capturada con esta distinción. Muchos de los principios jurídicos, prácticas sociales y visiones de mundo más importantes del presente pueden ser adecuadamente descritos desde la idea de una época de cosmopolitismo. La instalación del tribunal penal internacional en La Haya, la creciente positivización jurídica de la declaración universal de los derechos humanos en distintas convenciones regionales (europea, americana), los movimientos sociales que actúan a escala global y en defensa de principios cosmopolitas, son todos expresiones reales que refieren a una época que no puede ser entendida sin alguna clase de noción de cosmopolitismo. Pero, al mismo tiempo, fenómenos como el proteccionismo económico expresado en los subsidios agrícolas de los países del norte, el levantamiento de muros fronterizos para dificultar los desplazamientos de individuos y la permanente reaparición de tentaciones neo-imperialistas no sólo no pueden ser descritas como cosmopolitas sino que se plantean en abierta oposición al cosmopolitismo. Difícilmente podemos entonces describir los tiempos que corren como una época propiamente cosmopolita. De un modo similar, muchos de los problemas sociales más urgentes de las sociedades contemporáneas se insertan nítidamente en el horizonte cosmopolita que hemos venido describiendo. Como programa teórico que tiene una pretensión universalista tanto a nivel descriptivo como normativo, una perspectiva cosmopolita es pertinente para comprender, por ejemplo, los siguientes temas: las transformaciones jurídicas que están afectando la aún en ciernes “sociedad mundial” (Mereminskaya y Mascareño, 2005), las características específicas de las prácticas migratorias a inicios del siglo XXI (Schiller y Levitt, 2004; Wimmer y Schiller, 2002); el calentamiento global y los riesgos ecológicos de escala planetaria (Beck, 2002); el surgimiento, 
expansión y potencialidades aún insospechadas de las tecnologías de la información (Castells, 1996); el derecho al asilo (Derrida, 1997) y los crímenes contra la humanidad como figura jurídica efectivamente punible (Arendt, 1992; Hirsch, 2003). El cosmopolitismo tiene aquí un rol que cumplir no sólo en la descripción y explicación de estos casos sino también en lo que dice relación con su evaluación normativa.

Tal como no es preciso caracterizar a toda la tradición intelectual que hemos revisado como estrictamente cosmopolita, tampoco es adecuado afirmar que existe una única tradición cosmopolita que ha permanecido inmutable, ni tampoco que en el presente ha conseguido desembarazarse definitivamente de la carga metafísica de su canon filosófico. Sí es razonable sostener, sin embargo, que universalismo y cosmopolitismo han evolucionado conjuntamente y son, por tanto, intrínsecamente compatibles. En la actualidad, la conexión entre universalismo y cosmopolitismo se manifiesta en que, crecientemente, el marco normativo que mejor acomoda las pretensiones conceptuales de la teoría social del siglo XXI es aquel que se funda en aquello que es preferible para el conjunto de los individuos que habitan el planeta.

\section{REFERENCIAS}

Apel, K-O. (1994): "Narración Autobiográfica del Proceso Filosófico Recorrido con Habermas”. En E. Dussel (comp.), Debate en torno a la Ética del Discurso de Apel. México D. F.: Siglo XXI.

Arendt, H. (1992): Eichman in Jerusalem. London: Penguin.

Beck, U. (2000): "The Cosmopolitan Perspective: Sociology of the Second Age of Modernity”. En British Journal of Sociology, 51 (1): 79-105.

(2002): "The Cosmopolitan Society and its Enemies". En Theory, Culture \& Society, 19 (1-2): 17-44.

(2004: "Cosmopolitan Realism: On the Distinction between Cosmopolitanism

in Philosophy and the Social Sciences”. Global Networks, 4 (2): 131-156.

(2006): Cosmopolitan Vision. Cambridge: Polity Press.

Beck, U. y N. Sznaider (2006): "Unpacking Cosmopolitanism for the Social Sciences: A Research Agenda”. En British Journal of Sociology, 57 (1): 1-22.

Bottici, C. (2003): “The Domestic Analogy and the Kantian Project of Perpetual Peace”. En The Journal of Political Philosophy, 11 (4): 392-410.

Calhoun, C. (ed.) (1992): Habermas and the Public Sphere. Massachusetts: MIT Press. (2002): "The Class Consciousness of Frequent Travellers: Towards a Critique of Actually Existing Cosmopolitanism”. En S. Vertovec y R. Cohen (eds.), Conceiving Cosmopolitanism: Theory, Context, and Practice. Oxford: Oxford University Press.

Caney, S. (2002): “Cosmopolitanism and the Law of Peoples". En The Journal of Political Philosophy, 10 (1): 95-123. 
Cassirer, E. (1993): Kant. Vida y Doctrina. México D. F.: Fondo de Cultura Económica. Castells, M. (1996): The Rise of the Network Society. Oxford: Blackwell.

Chernilo, D. (2002): "The Theorization of Social Co-ordinations in Differentiated Societies. The Theory of Generalized Symbolic Media in Parsons, Luhmann and Habermas”. En British Journal of Sociology, 53 (3): 431-449.

(2004): "La Sociedad como Ideal Regulativo”. http://www.moebio.uchile.cl/21/ frames02.htm

(2006a): ‘Social Theory’s Methodological Nationalism: Myth and Reality”. En European Journal of Social Theory, 9 (1): 5-22.

(2006b): "Methodological Nationalism and its Critique". En G. Delanty y

K. Kumar (eds.), The SAGE Handbook of Nations and Nationalism. London: Sage.

(2007a): A Social Theory of the Nation-State: The Political Forms of Modernity beyond Methodological Nationalism. London: Routledge.

(2007b): "A Quest for Universalism: Re-Assessing the Nature of Classical Social Theory's Cosmopolitanism”. En European Journal of Social Theory, 10 (1): $17-35$.

Chernilo, D. y A. Mascareño (2005): "Universalismo, Particularismo y Sociedad Mundial: Obstáculos y Perspectivas de la Sociología en América Latina”. En Persona y Sociedad, 19 (3): 17-45.

De Grieff, P. (2002): 'Habermas on Nationalism and Cosmopolitanism'. En Ratio Juris, 15 (4): 418-438.

D’Entrèves, A. (1970): Natural Law. London: Hutchinson

Delanty, G. (2006): "Nationalism and Cosmopolitanism: The Paradox of Modernity". En G. Delanty y K. Kumar (eds), The SAGE Handbook of Nations and Nationalism. London: Sage.

Derrida, J. (1997): Cosmopolites de Tous les Pays, Encore un Efort! Paris: Galilée.

Donnelly, J. (1980): “Natural Law and Right in Aquinas' Political Thought”. En The Western Political Quarterly, 33 (4): 520-535.

Durkheim, É. (1966): Lecciones de Sociología. Buenos Aires: Shapire.

Emmet, D. (1994): The Role of the Unrealisable: A Study in Regulative Ideals. New York: St. Martin's Press.

Fine, R. (2001): Political Investigations. Hegel, Marx, Arendt. London: Routledge. (2003): “Kant's Theory of Cosmopolitanism and Hegel's Critique”. En Philosophy and Social Criticism, 29 (6): 609-630.

(2004): “Cosmopolitismo sin 'Ismo': Un Ensayo Reconstructivo”. En Persona y Sociedad, XVIII (2): 239-262.

(2006a): “Cosmopolitanism and Violence: Difficulties of Judgment”. En British Journal of Sociology, 57 (1): 49-67.

- (2006b): “Cosmopolitanism: A Social Science Research Agenda”. En G. Delanty (ed.), Handbook of European Social Theory. London: Routledge. (2007): Cosmopolitanism. London: Routledge.

Fine, R. y V. Boon (2007): “Cosmopolitanism: Between Past and Future”. En European Journal of Social Theory, 10 (1): en prensa.

Fine, R. y D. Chernilo (2004): "Between Past and Future: The Equivocations of the New Cosmopolitanism”. En Studies in Law, Politics, and Society, 31: 25-44.

Fine, R. y W. Smith (2003): “Jürgen Habermas's Theory of Cosmopolitanism”. En Constellations, 10 (4): 469-487. 
Finnis, J. (1999): “Natural Law and the Ethics of Discourse”. En Ratio Juris, 12 (4): 354373.

Friedrich, C. (1964): La Filosofía del Derecho. México D. F.: Fondo de Cultura Económica.

Habermas, J. (1975): Problemas de Legitimación en el Capitalismo Tardío. Buenos Aires: Amorrortu.

(1985): Conciencia Moral y Acción Comunicativa. Barcelona: Península. (1987): Teoría y Praxis. Madrid: Tecnos.

(1989a): Teoría de la Acción Comunicativa, 2 volúmenes. Buenos Aires: Taurus.

- (1989b): Teoría de la Acción Comunicativa: Complementos y Estudios Previos. Madrid: Cátedra.

(1990a): Conocimiento e Interés. Madrid: Taurus.

(1990b: Pensamiento Postmetafísico. Madrid: Taurus.

(1992): Ciencia y Técnica como Ideología. Madrid: Tecnos.

(1993): El Discurso Filosófico de la Modernidad. Madrid: Taurus.

(1994): Historia y Crítica de la Opinión Pública. Madrid: GG Mass Media.

(1998): Facticidad y Validez. Madrid: Trotta.

(1999a): La Inclusión del Otro. Barcelona: Paidós.

(1999b): "Introduction to Ratio Juris Special Issue on Between Facts and Norms”. En Ratio Juris, 12 (4): 329-335.

(2000): La Constelación Postnacional. Barcelona: Paidós.

- (2001): “Why Europe Needs a Constitution?” En New Left Review, 11

(September-October) 5-26.

(2002): Acción Comunicativa y Razón sin Trascendencia. Barcelona: Paidós.

(2004): Tiempo de Transiciones. Madrid: Trotta.

(2006): El Occidente Escindido. Madrid: Trotta.

Hegel, G. ([1802-3] 1975): Natural Law. Filadelfia: University of Pennsylvania Press.

Held, D. (1995): Democracy and the Global Order. From the Modern State to Cosmopolitan Governance. Cambridge: Polity Press.

Hirsh, D. (2003): Law against Genocide: Cosmopolitan Trials. London: Glasshouse Press.

Hochstrasser, T. (2000): Natural Law Theories in the Early Enlightenment. Cambridge: Cambridge University Press.

Kant, I. ([1784] 1994a): "Idea de una Historia Universal con Sentido Cosmopolita”. En

I. Kant, Filosofía de la Historia. México D. F.: Fondo de Cultura Económica.

- ([1784] 1994b): “¿Qué es la Ilustración?” En I. Kant, Filosofía de la Historia.

México D. F.: Fondo de Cultura Económica.

([1795] 2001): La Paz Perpetua. Un Bosquejo Filosófico. Buenos Aires:

Longseller.

- (2002): Crítica de la Razón Pura. Madrid: Alfaguara.

La Torre, M. (2006): "On Two Distinct and Opposing Versions of Natural Law:

'Exclusive’ versus ‘Inclusive”’. En Ratio Juris, 19 (2): 197-216.

Lafont, C. (1993): La Razón como Lenguaje. Madrid: Visor.

(2004): "Moral Objectivity and Reasonable Agreement: Can Realism Be

Reconciled with Constructivism”. En Ratio Juris, 17 (1): 27-51.

Lewis, E. (1940): "Natural Law and Expediency in Medieval Political Theory”. En Ethics, 50 (2): 144-163. 
McCarthy, T. (1987): La Teoría Crítica de Jürgen Habermas. Madrid: Tecnos.

Mereminskaya, E. y A. Mascareño (2005): "La Desnacionalización del Derecho y la Formación de Regímenes Globales de Gobierno”. En M. Martinic y M. Tapia (eds.), Sesquicentenario del Código Civil de Andrés Bello: Pasado, Presente y Futuro de la Codificación, Tomo II. Santiago: Lexis-Nexis, 1391-1427.

Nussbaum, M. (1997): “Kant and Stoic Cosmopolitanism”. En Journal of Political Philosophy, 5 (1): 1-25.

Rawls, J. (1999): The Laws of Peoples. Harvard: Harvard University Press.

Schiller, N. y P. Levitt (2004): "Conceptualizing Simultaneity: A Transnational Social Field Perspective on Society”. En International Migration Review, 38 (3): 10021039.

Schneewind, J. (1993): “Kant and Natural Law Ethics”. En Ethics, 104 (1): 53-74.

Strauss, L. (1974): Natural Right and History. Chicago: The University of Chicago Press.

Toulmin, S. (1990): Cosmopolis. The Hidden Agenda of Modernity. Chicago: The University of Chicago Press.

Turner, B. S. (1990): “The Two Faces of Sociology: Global or National?”. En M. Featherstone (ed.), Global Culture. Nationalism, Globalisation and Modernity. London: Sage.

(2006): “Classical Sociology and Cosmopolitanism: A Critical Defence of the Social”. En British Journal of Sociology, 57 (1): 133-155.

(2004): “Jürgen Habermas: European or German?” En European Journal of Political Theory, 3 (3): 293-314.

Vertovec, S. y R. Cohen (2002) (eds.): Conceiving Cosmopolitanism: Theory, Context, and Practice. Oxford: Oxford University Press.

Webster, F. (2002): Theories of the Information Society. London: Routledge.

Wimmer, A. y N. Schiller (2002): "Methodological Nationalism and Beyond: NationState Building, Migration and the Social Sciences”. En Global Networks, 2 (4): 301-334.

Zolo, D. (1999): “A Cosmopolitan Philosophy of International Law? A Realist Approach”. En Ratio Juris, 12 (4): 429-444. 